\title{
Comparison of Aerobic Exercise and Combination Exercise Program on Overall Physical Fitness and Mental Health in 20 Aged Subjects with Obesity
}

\author{
Eun-Sang Lee, MS • Gyeong-Tae Kim, PhD • Seung-Won Lee, $\mathrm{PhD}^{2 \dagger}$ \\ Department of Physical Therapy, Graduate School of Sahmyook University \\ ${ }^{1}$ Department of Physical Therapy, Gwang-ju Health University \\ ${ }^{2}$ Department of Physical Therapy, Sahmyook University
}

Received: July 7, 2016 / Revised: July 20, 2016 / Accepted: August 7, 2016

(c) 2016 J Korean Soc Phys Med

\begin{abstract}
| Abstract |
PURPOSE: The purpose of this study is to compare the effects of aerobic exercise and combination exercise on physical fitness, body composition, and depression and to observe the relationship between obesity and depression.
\end{abstract}

METHODS: A total of 40 obese people were divided into an aerobic exercise group $\left(\mathrm{n}_{1}=20\right)$ and a combination exercise group $\left(\mathrm{n}_{2}=20\right)$ that was performed swiss ball exercise and aerobic exercise. Each group exercised three times per week for eight weeks. Outcome measures were basic physical fitness, body composition, and depression.

RESULTS: After completion of the exercise, there was a significant difference in overall physical fitness factors of percentage body fat (\%body fat), strength, muscle endurance, flexibility, cardiovascular endurance in the combination exercise group $(\mathrm{p}<.05)$. Strength, muscle endurance, flexibility, and cardiovascular endurance were more improved in the combination exercise group than aerobic

†Corresponding Author : swlee@syu.ac.kr

This is an Open Access article distributed under the terms of the Creative Commons Attribution Non-Commercial License (http://creativecommons.org/licenses/by-nc/3.0) which permits unrestricted non-commercial use, distribution, and reproduction in any medium, provided the original work is properly cited. exercise group $(\mathrm{p}<.05)$. However, changes of $\%$ body fat and psychological factor between the two groups were not significant.

CONCLUSION: Combination exercise program has an effect on the solution of obesity in physical development and strength. Therefore, it seems to that use with better perform both aerobic exercise and Swiss ball exercise. In addition, the Swiss ball exercise, which is an easy, convenient and economical self-exercise that can be done at home, is recommended due to its positive effects on physical establishment and fitness.

Key Words: Exercise, Obesity, Physical fitness, Depression

\section{Introduction}

According to a community Health Survey, the obesity rate in Korea is increasing by $22 \%$ every year. Obesity can cause health life threatening diseases including metabolic syndrome, hypertensivity, and diabetes (Shin et al., 2015a). Katzmarzyk et al. (2003) have mentioned that the most direct factor among the factors causing obesity is the lack of physical activity. Because of this, obesity can decrease strength, muscle endurance, flexibility and 
Table 1. Demographic characteristics of the subjects

\begin{tabular}{llll}
\hline & \multicolumn{1}{c}{ AEG $\left(\mathrm{n}_{1}=20\right)$} & \multicolumn{1}{c}{ CEG $\left(\mathrm{n}_{2}=20\right)$} & \multicolumn{1}{c}{$\mathrm{t} / \mathrm{x}^{2}(\mathrm{p})$} \\
\hline Age $($ year $)$ & $23.10 \pm 3.14$ & $22.30 \pm 2.70$ & $.86(.39)$ \\
Gender (male/female) & $10 / 10$ & $10 / 10$ & $.00(1.00)$ \\
Height $(\mathrm{cm})$ & $167.90 \pm 8.18$ & $168.46 \pm 7.95$ & $-.22(.83)$ \\
Weight $(\mathrm{kg})$ & $75.41 \pm 19.16$ & $71.66 \pm 16.27$ & $.67(.51)$ \\
Body fat $(\%)$ & $27.50 \pm 5.67$ & $27.25 \pm 3.73$ & $.17(.87)$ \\
\hline
\end{tabular}

Values are presented as mean $\pm \mathrm{SD}$.

AEG: Aerobic exercise group, CEG: Combination exercise group.

power, which can that bring about metabolic abnormalities.

Thus, efficient exercise program for the obese that enable weight control for maintenance and improvement of fitness is necessary (Kim et al., 2003).

For the development of efficient exercise program, a variety of studies are being performed such as aerobic exercise (Keating et al., 2015), pilates (Cakmakci, 2011), endurance exercise (Taniguchi et al., 2016), and high intensity interval training (Fisher et al., 2015). Among them, aerobic exercise, which is the most popular, has been proven to be effective in terms of cost and time, but according to a recent study, a combination exercise program has a more positive effect on the health related fitness factors of strength, muscle endurance, flexibility, power in addition to physiology (Kim and Kim, 2016; $\mathrm{Na}$ and Seo, 2001). Combination exercise refers to an exercise that combines more than 2 types of exercise. It is especially effective when aerobic exercise and strength exercise are combined (Back and Oh, 2015; Yang, 2015).

Meanwhile, according to the study by Dixon et al. (2003), obese people usually have depression. Other studies also suggest the correlation of obesity with depression and stress (Dong et al., 2004; Onyike et al., 2003).

Thus, the aims of this study were to compare the effects of aerobic exercise and combination exercise on overall physical fitness and mental health in 20s aged adults with obesity and to provide the effective exercise program for obesity in accordance with solving a psychiatric problem.

\section{Methods}

\section{Subjects}

For the study, 31 obese men with over $22 \%$ of body fat and 33 obese women with over $28 \%$ of body fat among 316 adults at G-University were selected with a reference to the study of Shin et al. (2015b). Inclusion criteria were those did not participate in regular exercise for 6 months previously and those without any medical abnormalities. Nine adults (3 men, 6 women) who participated in regular exercise for the last 6 months and eight adults $(6$ men, 2 women) who did not agree with the voluntary participation with the understanding of the purpose and intention of the study were excluded. Seven adults ( 2 men, 5 women) gave up participating in the study during pretest. A total of 40 adults with obesity finally participated. This study was conducted as a single blind, randomized, clinical trial. Participants were randomly assigned to either aerobic exercise group or combination exercise group, stratified by gender (man or woman). To ensure blinding to group allocation, drawing a lot method was used. The physical characteristics of the subjects are shown on Table 1.

\section{Procedure}

The exercise was performed for 8 weeks. Prior to the experiment, the health related physical strength was measured at G-university health center, and the mental health measurement was done through questionnaires. 
Depending on the purpose of the experiment, 10 men and 10 women were assigned to the aerobic exercise group and the combination exercise group respectively. The values were measured before and after exercise, and the average values were compared between two groups. And physical and psychological effects of two types of exercise were studied.

\section{Assessment}

1) Assessment of percentage body fat

A percentage body fat ( $\%$ body fat) was calculated by biological resistance value that was measured by the method of bioelectrical impedance analysis (BIA) using Inbody 720 (Inbody 720, Biospace, Korea). Subjects maintained an anatomical position on the tester for 3 minutes. The changing of obesity was assessed by the change of \%body fat, which is the index of obesity, for the comparison of before and after solutions for obesity (Chu and Lee, 2013; Kim et al., 2011).

\section{2) Assessment of basic physical fitness}

Basic physical fitness evaluation of the study was conducted based on the Park (2002). For the strength test, the participants stood on the board by using SH-2000E (SH-2000E, O2 run, Japan), which is a back strength tool with knees and feet extended, and then strongly pulled the upper extremity upwards with gradual strength by adjusting the length of metal chain to hold the handle when upper extremity was at a flexion of 30 degrees. It was done two times and measured with the unit of $\mathrm{kg}$.

For the muscle endurance test, SH-2000N (SH-2000N, $\mathrm{O} 2$ run, Japan) was used. On the sit-up measurement board, at a supine position, the knees were in flexion and both hands were on the back of the neck, by raising the upper extremity using only the abdominis. A flexion forward was performed for 30 seconds, and the frequency was measured. For the flexibility test, by using SH-2000G (SH-2000G,
O2 run, Japan), which is the tool for sitting sit-ups, the participants had their knees extended and stretched their hands forward, and then they did flexions of the trunk two times. The highest value was measured with the unit of $\mathrm{cm}$.

Regarding the cardiovascular endurance test, the method that uses Aeroobike75XL II (Aeroobike75XL II, O2 run, Japan), in which strength gradually increases. Duration time of exercise and heart rate of recovery period were measured, and then the level of cardiovascular endurance was estimated.

3) Assessment of mental health

Change of mental health is what translated depression's measurement tool Center for Epidemiologic Studies Depression Scale (CES-D) with a reference to the study of Park et al. (2007) and CES-D is the depression scale is the tool for primary selection of depression Jo and Kim (1993) translated. This measurement is a self-reporting type of questionnaire with 20 items. The types of depression that participants experienced the last week were measured in 4 stages. The intensity of the symptoms was categorized by a 4 point Likert scale, in which 'rarely' was 0 , 'sometimes' was 1, 'often' was 2, and 'mostly' was 3 . The total points of all the question's ranged from 0 to 60 , the positive questions $(5,10,15)$ were reverse coded, and higher scores meant higher depression. The reliability of Korean CES-D tool used in this study was proven to be high internal consistency reliability $(\alpha=.89)$, and the score of 21 was used for clinical efficacy because it wasn't used for a clinical tool but for the purpose of finding out the overall mental health condition (Jo and Kim, 1993).

\section{Exercise method}

1) Combination exercise program

The exercise program used in this study was organized with the Swiss ball program of revision and compensation, with reference to the study by Ahn et al. (2008) and Lee 
et al. (2012). The Swiss ball program is consisted of warm up, main exercise, and cool down stages. Regarding the combination exercise, which is the combination of aerobic exercise and Swiss ball exercise, Swiss ball exercise is lay hands on the ball push up, sit-up, lifting body with open arms, stretched knee with hip lift, bent knee and extension, jackknife. It consisted of a total of six movements. Aerobic exercise was done three times a week for 20 minutes each time with $60 \sim 70 \%$ strength of heart rate maximum (HRmax) that the American college of sports medicine (ACSM, 2006) recommended (Kim, 2010). Regarding the Swiss ball exercise, rating of perceived exertion (RPE) was applied, and the strength of "somewhat hard" in "fairly light", which is the strength of $10 \sim 15$ repetition maximum $(\mathrm{RM})$, was applied. Three sets of 10 15 times were done sequentially and the rest was 1 minute and 20 minutes per day.

\section{2) Aerobic exercise program}

For the aerobic exercise program, 20 minutes of treadmill and 20 minutes of aerobike were used with 60 $70 \%$ strength of personal HRmax that the American college of sports medicine (ACSM, 2006) recommended (Kim, 2010). The exercise was done for 8 weeks, three times per week and 60 minutes a day, which consisted of 10 minutes of warm up, 40 minutes of main exercise and 10 minutes of cool down.

\section{Data analysis}

All statistical analysis was used as SPSS ver. 21.0 (SPSS Inc., Chicago, USA), and all variables were calculated mean and standard deviation. Shapiro-Wilk method was used for normality test of all subjects. Independent t-test and chi-square test were used for homogeneity test between two groups. To distinguish the difference of both groups \%body fat, strength, muscle endurance, flexibility and cardiovascular endurance, independent t-test was done. To discover the change before and after the experiment, paired t-test was done. The statistical significance was set at $\alpha=.05$.

\section{Results}

1. Comparison of percentage body fat between two groups

In the \%body fat result of comparing the effectiveness between each group according to the difference before and after experiment showed that the combination exercise was $2.20 \pm 1.50 \%$, which was more statistically significant than the aerobic exercise, which was $1.25 \pm .88 \%(\mathrm{p}<.05)$ (Table 2).

\section{Comparison of Basic physical fitness between two groups}

The change of strength is the result of comparing the effectiveness between each group according to the difference before and after experiment showed that the

Table 2. Comparison of the Percentage Body Fat

\begin{tabular}{lllll}
\hline & & \multicolumn{1}{c}{ AEG $\left(\mathrm{n}_{1}=20\right)$} & \multicolumn{1}{c}{ CEG $\left(\mathrm{n}_{2}=20\right)$} & $\mathrm{t}(\mathrm{p})$ \\
\hline & Pre-test & $27.50 \pm 5.67$ & $27.25 \pm 3.73$ & $.17(.87)$ \\
$\%$ Body Fat & Post-test & $26.26 \pm 5.76$ & $25.05 \pm 4.44$ & \\
$(\%)$ & Change value & $1.25 \pm .88$ & $2.20 \pm 1.50$ & $2.45(.19)$ \\
& $\mathrm{t}(\mathrm{p})$ & $6.30(.00)$ & $6.55(.00)$ & \\
\hline
\end{tabular}

Values are presented as mean $\pm \mathrm{SD}$.

AEG: Aerobic exercise group, CEG: Combination exercise group. 
Table 3. Comparison of the Basic physical fitness

\begin{tabular}{lllll}
\hline & & AEG $\left(\mathrm{n}_{1}=20\right)$ & CEG $\left(\mathrm{n}_{2}=20\right)$ & $\mathrm{t}(\mathrm{p})$ \\
\hline \multirow{3}{*}{$\begin{array}{l}\text { Back muscle } \\
\mathrm{kg})\end{array}$} & Pre-test & $97.35 \pm 29.85$ & $89.24 \pm 29.89$ & $.86(.40)$ \\
& Post-test & $99.10 \pm 28.80$ & $92.55 \pm 29.81$ & \\
& Change value & $1.75 \pm 1.97$ & $3.31 \pm 1.61$ & $-2.74(.01)$ \\
& $\mathrm{t}(\mathrm{p})$ & $-3.97(.00)$ & $-9.19(.00)$ & \\
Muscle endurance & Pre-test & $18.55 \pm 4.26$ & $17.80 \pm 4.18$ & $.56(.58)$ \\
$($ inning $)$ & Post-test & $20.15 \pm 4.28$ & $20.35 \pm 4.56$ & \\
& Change value & $1.60 \pm 1.23$ & $2.55 \pm 1.40$ & $-2.28(.03)$ \\
& $\mathrm{t}(\mathrm{p})$ & $-5.81(.00)$ & $-8.18(.00)$ & \\
Flexibility & Pre-test & $5.99 \pm 7.41$ & $7.28 \pm 6.72$ & $-.58(.87)$ \\
$(\mathrm{cm})$ & Post-test & $6.76 \pm 7.59$ & $9.40 \pm 5.56$ & \\
& Change value & $.77 \pm .94$ & $2.13 \pm 2.00$ & $-2.75(.01)$ \\
& $\mathrm{t}(\mathrm{p})$ & $-3.68(.00)$ & $-4.76(.00)$ & \\
\hline \multirow{4}{*}{ Cardiovascular $)$} & $31.95 \pm 7.79$ & $31.25 \pm 7.36$ & $.29(.77)$ \\
$(\mathrm{ml} / \mathrm{kg} /$ min) & Pre-test & $32.95 \pm 8.05$ & $34.80 \pm 7.68$ & \\
& Post-test & $1.00 \pm .18$ & $3.55 \pm 1.99$ & $-4.22(.00)$ \\
& Change value & $-2.44(.03)$ & $-7.99(.00)$ & \\
\hline
\end{tabular}

Values are presented as mean $\pm \mathrm{SD}$.

AEG: Aerobic exercise group, CEG: Combination exercise group.

combination exercise group was $3.31 \pm 1.61 \mathrm{~kg}$, and the aerobic exercise group was $1.75 \pm 1.97 \mathrm{~kg}$, which showed statistically significant differences $(\mathrm{p}<.05)$ (Table 3$)$.

The change of muscle endurance is the result of comparing the effectiveness between each group according to the difference before and after experiment showed that the combination exercise group was $2.55 \pm 1.40$ inning and the aerobic exercise group was $1.60 \pm 1.23$ inning, which means the combination exercise group was statistically significantly effective $(\mathrm{p}<.05)$ (Table 3$)$.

Change of flexibility is the aerobic exercise group, the result of comparing the effectiveness between each group according to the difference before and after experiment showed that the combination exercise group was $2.13 \pm 2.00$ $\mathrm{cm}$, and the aerobic exercise group was $.77 \pm .94 \mathrm{~cm}$. The combination exercise group showed statistically more significant increased $(\mathrm{p}<.05)$ (Table 3).

Change of cardiovascular endurance is the result of comparing the effectiveness between each group according to the difference before and after experiment showed that the combination exercise group was $3.55 \pm 1.99 \mathrm{ml} / \mathrm{kg} / \mathrm{min}$, and aerobic exercise group was $.85 \pm .24 \mathrm{ml} / \mathrm{kg} / \mathrm{min}$. The combination exercise group showed statistically more significant increase $(\mathrm{p}<.05)$ (Table 3$)$.

\section{Comparison of Psychological factor change between two groups}

In the depression scale result of comparing aerobic exercise group the result of comparing the effectiveness between each group according to the difference before and after experiment showed that both groups didn't show statistically significant differences ( $p>05$ ) (Table 4). 
Table 4. Comparison of the depression

\begin{tabular}{lllll}
\hline & & \multicolumn{1}{c}{ AEG $\left(\mathrm{n}_{1}=20\right)$} & \multicolumn{1}{c}{ CEG $\left(\mathrm{n}_{2}=20\right)$} & $\mathrm{t}(\mathrm{p})$ \\
\hline & Pre-test & $24.70 \pm 6.43$ & $25.25 \pm 4.49$ & $-.20(.84)$ \\
& Post-test & $23.85 \pm 4.11$ & $24.30 \pm 3.76$ & \\
CES-D & Change value & $.85 \pm 4.24$ & $.75 \pm 4.64$ & $-.07(.94)$ \\
(points) & $\mathrm{t}(\mathrm{p})$ & $.86(.40)$ & $.72(.48)$ & \\
\hline
\end{tabular}

Values are presented as mean $\pm \mathrm{SD}$.

CES-D: Center for Epidemiologic Studies Depression Scale, AEG: Aerobic exercise group, CEG: Combination exercise group.

\section{Discussion}

From the perspective of basic physical fitness improvement, various exercises can improve power and coordination and develop the capillary. In addition, they improve blood flow and increase the effectiveness of various bodily activities including daily maintenance due to the improvement of protein supplement and strength (Albert et al., 2003).

According to the study of Kim and Kim (2016), after combination exercise was done on an obese college woman for 12 weeks, the \%body fat decreased along with significant effectiveness of strength, power, muscle endurance and cardiovascular endurance. In this study, the combination exercise with the use of the Swiss ball exercise, which is effective on basic physical fitness, was done. It brought about significant effectiveness in strength $(p=.01)$, muscle endurance $(p=.03)$, flexibility $(p=.01)$ and cardiovascular endurance $(\mathrm{p}=.00)$ compared to the aerobic exercise. As a result, combination exercises are involved in the development of physical structure, so they help with activity of energy and cause organized contraction and relaxation of muscles, increasing the amount of muscles (Yang, 2009). In addition, combination exercises improve the strength of regular bodily activities, are highly correlated to the number of motor units, increase impulse frequency and increase cross section areas (Kim and Jung, 2007), and bring about improvement of strength by improving the flexibility of muscles, ligaments and tendons (Kim and Jung, 2007).

The increase of endorphins through exercise reduces the negative aspects of human mentality and increases social interaction, affecting the improvement of psychological functions (Peluso and Guerra de Andrade, 2005). According to the study by Eunkook et al. (1998), bodily activities have a positive effect on mental health and well-being and gradually reduce the negative emotions of anxiety and depression.

Stunkard et al. (2003) claimed obesity has significant correlation with depression. Various precedent studies also confirmed the correlation of obesity with depression (Dixon et al., 2003; Dong et al., 2004; Onyike et al., 2003; Roberts and Duong, 2015).

Nevertheless, in the study by Faith et al. (2002), there is correlation between obesity and depression, but it isn't statistically significant to explain the relationship with only one variable. In this study, there is comparison analysis between aerobic exercise that can improve the psychiatric function and the balance exercise that can enhance effectiveness of the aerobic exercise, but there was no significant difference in obesity related depression $(p=.09)$.

It seems that no significant difference appeared in this study because the exercises didn't bring about noticeable effectiveness compared to the expectation levels of in the most precedent studies concerning obesity depression, 12 weeks of mediation was given, but in this study, only 8 weeks was given. For a more exact result, relatively high 
exercise strength and long-term exercise programs need to be applied, and the study about mental function change for obese people is also needed.

In addition, this study by for people for the limitation did not control the everyday common dietary and daily patterns according to the person.

\section{Conclusion}

In conclusion, combination exercise programs have an effect on the solution of obesity in physical development and strength. Therefore, it seems to that use with better perform both aerobic exercise and Swiss ball exercise. In addition, there is a need for studies concerning the psychological factors through long-term training rather than short-term.

\section{References}

ACSM. Guidelines for exercise testing and prescription $\left(7^{\mathrm{TH}}\right.$ ed). Philadelpia. Lippincott Williams \& Wilkins. 2006.

Ahn BY, Kim WW, Park SY. Effects of elastic band and swiss ball exercise in body composition and blood components on obese woman college students. The Official Journal of the Korean Association of Certified Exercise Professionals. 2008;10(1):17-26.

Albert VC, Lawrence RB, Mark AE, et al. Do Individual Perceptions of Group Cohesion Reflect Shared Beliefs? An Empirical Analysis. Small Group Research. 2003;34(4):468-96.

Back SU, Oh DJ. Impact of different events of sports on the body composition and blood lipids of overweight middle school boys. The Korea Journal of Sports Science. 2015;24(2):1303-13.

Cakmakci O. The effect of 8 week pilates exercise on body composition in obese women. Coll Antropol.
2011;35(4):1045-50.

Chu M, Lee MH. Comparison of Body Composition of College Students after 4week Jump-roping Exercise. J Korean soc phys med. 2013;8(4):627-35.

Dixon JB, Dixon ME, O'Brien PE. Depression in association with severe obesity: changes with weight loss. Arch Intern Med. 2003;163(17):2058-65.

Dong C, Sanchez LE, Price RA. Relationship of obesity to depression: a family-based study. Int J Obes Relat Metab Disord. 2004;28(6):790-5.

Eunkook S, Diener ED, Shigehiro O, et al. TriandisThe Shifting Basis of Life Satisfaction Judgments Across Cultures: Emotions Versus Norms Journal of Personality and Social Psychology. 1998;74(2):482-93.

Faith MS, Matz PE, Jorge MA. Obesity-depression associations in the population. J Psychosom Res. 2002;53(4): 935-42.

Fisher G, Brown AW, Bohan Brown MM, et al. High Intensity Interval- vs Moderate Intensity Training for Improving Cardiometabolic Health in Overweight or Obese Males: A Randomized Controlled Trial. PLoS One. 2015;10(10):e0138853.

Katzmarzyk PT, Janssen I, Ardern CI. Physical inactivity, excess adiposity and premature mortality. Obes. 2003;4(4): 257-70.

Keating SE, Hackett DA, Parker HM, et al. Effect of aerobic exercise training dose on liver fat and visceral adiposity. J Hepatol. 2015;63(1):174-82.

Kim HA, Seo KC, Lim SW, et al. Analysis of the Chest Expansion and Pulmonary Function in the 20s men Obesity according to Position Change. J Korean soc phys med. 2011;6(3):247-56.

Kim KJ, Hong CB, Park JS, et al. Comparison of Blood Concentrations of Lipid Profiles Among Subtype of Obesity in Adult. Korean J Nutr. 2003;7(3):39-43.

Kim MI, Jung DC. The Effects of 12Weeks Combined Training on Body Composition Physical Fitness and Blood Constituent in Female College Students. The Korea 
Journal of Sports Science. 2007;16(1):473-81.

Kim NJ. The Effects of Aerobic exercise, Aerobic exercise and Pilates exercise on Coronary Artery Disease risk factor in Postmenopausal Obese Women. Journal of Korean Physical Education Association for Girls and Women. 2010;24(1):1-10.

Kim WH, Kim SS. The effects of combined exercise training 12weeks on body composition and basic physical strength in obese college women. Journal of Digital Convergence. 2016;14(4):471-8.

Lee CW, Kim IS, Lee IS. The Effects of Combination Patterns of Proprioceptive Neuromuscular Facilitation and Ball Exercise on Pain and Balance in Chronic Back Pain Patients. J Korean soc phys med. 2012;7(1):1-9.

Na JC, Seo HG. Effect of 12 weeks Combined Running and Muscular Resistance Exercise on Physical Fitness in Obese Female. The Korean Journal of Physical Education. 2001;40(1):440-7.

Onyike CU, Crum RM, Lee HB, et al. Is obesity associated with major depression? Results from the Third National Health and Nutrition Examination Survey. Am J Epidemiol. 2003;158(12):1139-47.

Park HJ. The change of body composition \& physical fitness by weight control program : by female college students in Seoul. Master's Degree. Dongduk Women's University. 2002.

Peluso MA, Guerra de Andrade LH. Physical activity and mental health: the association between exercise and mood. Clinics (Sao Paulo). 2005;60(1):61-70.

Roberts RE, Duong HT. Does major depression affect risk for adolescent obesity? J Affect Disord. 2015;186 162-7.

Shin CW, Kim CK, Jang IY, et al. Changes of Biophysical and Physical Fitness Function on Combined Exercise Program in 20" Female University Students with Obesity according to Heights of Insole. The Journal of the Korea Contents Association. 2015a;15(10): $336-45$.

Shin CW, Kim CK, Jang IY, et al. Changes of Body Composition according to Exercise Type in Obesity Female Students. The Journal of the Korea Contents Association. 2015b;15(10):346-53.

Stunkard AJ, Faith MS, Allison KC. Depression and obesity. Biol Psychiatry. 2003;54(3):330-7.

Taniguchi H, Tanisawa K, Sun X, et al. Endurance Exercise Reduces Hepatic Fat Content and Serum Fibroblast Growth Factor 21 Levels in Elderly Men. J Clin Endocrinol Metab. 2016;101(1):191-8.

Yang YK. The Study of Correlation between Bone Mineral Density and Body Composition in College Women. The Korea Journal of Sports Science. 2009;18(4): 959-65.

Yang YK. The Effect of Quercetin Simultaneous Administration by Exercise Type for 12 Weeks on Blood Lipid and Obesity Index in Obese University Women. The Korea Journal of Sports Science. 2015;24(2):1255-68. 